Article

\title{
Formaldehyde, Oxidative Stress, and FeNO in Traffic Police Officers Working in Two Cities of Northern Italy
}

\author{
Giulia Squillacioti ${ }^{1}{ }^{(D}$, Valeria Bellisario ${ }^{1}$, Amelia Grosso ${ }^{2}{ }^{\oplus}$, Federica Ghelli ${ }^{1}$, \\ Pavilio Piccioni ${ }^{3}$, Elena Grignani ${ }^{4}$, Angelo Corsico ${ }^{2,+}+\left(\mathbb{C}\right.$ and Roberto Bono ${ }^{1, *,+(\mathbb{C})}$ \\ 1 Department of Public Health and Pediatrics, University of Torino, 10121 Torino, Italy; \\ giulia.squillacioti@unito.it (G.S.); valeria.bellisario@unito.it (V.B.); federica.ghelli@unito.it (F.G.) \\ 2 Division of Respiratory Diseases, S. Matteo Foundation-University of Pavia, 5001 Pavia, Italy; \\ amelia.grosso@gmail.com (A.G.); angelo.corsico@unipv.it (A.C.) \\ 3 Unit of Respiratory Medicine, National Health Service, ASL TO2, 10121 Torino, Italy; papiccioni@gmail.com \\ 4 Maugeri Scientific Clinical Institutes, 5001 Pavia, Italy; elena.grignani@icsmaugeri.it \\ * Correspondence: roberto.bono@unito.it; Tel.: +39-011-670-5818; Fax: +39-011-236-5818 \\ + These two authors equally contributed to the conception and execution of the study.
}

Received: 9 January 2020; Accepted: 2 March 2020; Published: 4 March 2020

\begin{abstract}
Personal air formaldehyde (air-FA) was measured as risk factor of airways inflammation and oxidative stress (SO) induction. Overall, 154 police officers were enrolled from two differently urbanised Italian cities, Turin and Pavia. Urinary F2t-isoprostane (15-F2t-IsoP), a prostaglandin-like compound, was quantified as a biomarker of general OS in vivo and fractional exhaled nitric oxide (FeNO) was measured for monitoring local inflammatory processes. Urinary cotinine was quantified as a biomarker of tobacco smoking exposure. Traffic police officers living in Turin showed an increased level of $\log$ air-FA $(p<0.001)$, equal to $+53.6 \%(p<0.001)$. Log air-(FA) mean values were 3.38 (C.I. 95\% 3.33-3.43) and 2.84 (C.I. 95\% 2.77-2.92) in Turin and Pavia, respectively. Log (air-FA) was higher in "outdoor workers" (3.18, C.I. 95\% 3.13-3.24, $p=0.035)$ compared to "indoor workers", showing an increase of $+9.3 \%$, even controlling for sex and city. The analyses on 15-F2t-IsoP and FeNO, both adjusted for log air-FA, highlighted that OS and inflammation were higher $(+66.8 \%, p<0.001$ and $+75 \%, p<0.001$, respectively) in Turin traffic police officers compared to those from Pavia. Our findings suggest that even low exposures to traffic-related emissions and urbanisation may influence both general oxidative stress levels and local inflammation.
\end{abstract}

Keywords: public health; traffic police officers; formaldehyde; 15-F2t-isoprostane; FeNO

\section{Introduction}

Due to their toxicological and/or carcinogenic properties, some volatile organic compounds (VOCs), aromatic hydrocarbons and carbonyls have increasingly gained attention in the international scientific community dealing with public health issues [1-3]. In the last decades, researchers, interested in non-communicable diseases and prevention, focused on the interaction between the aforementioned chemicals and human health, especially in preventive terms [4-6]. Formaldehyde (FA), the simplest among the aldehydes, is an ubiquitous pollutant in living and occupational environments [7].

FA may directly originate from natural sources, from several anthropogenic activities and from indirect product via the photochemical oxidations of hydrocarbons in the atmosphere [8,9]. FA has been detected in several occupational settings involving wood-based materials, laminates, paints and urea-based resins [10] and is used as disinfectant and preservative in hospitals and in pathology units [11]. According to the International Agency for Research on Cancer (IARC) [12] and the United 
States Environmental Protection Agency (US EPA) [13], FA is classified as a human carcinogen. FA-related exposures are connected to many other health effects, such as eye and respiratory tract irritations, allergic contact dermatitis and bronchial asthma [12,14].

Some previous studies investigated the influence of air pollution and FA on inflammation and Oxidative Stress (OS) induction $[11,15,16]$ and on DNA toxicity $[17,18]$. Conversely, data on personal exposure to FA and OS induction in urban air settings are still lacking. Exposure to environmental pollution may lead to OS and inflammation, which in turn are able to determine biological outcomes and health impairments [19]. Exposure to FA may enhance oxidant species and impair the antioxidant system leading to OS. This latter can result in structural and enzymatic changes in organs [20], cytotoxic effects [21] and carcinogenic processes.

Raffic police officers may undergo long-term exposures to traffic-related pollutants $[17,18]$. For this reason, they can represent a population model suitable to describe some potential risky conditions for health in urban settings. Therefore, this population was considered suitable to assess the exposition to outdoor and indoor FA and some potentially consequent health effects such as OS and airway inflammation.

Although air-FA is usually higher indoors, the exposure in outdoor environments may considerably contribute to the human daily intakes of FA, the concentration of which is extremely variable in relation to many aspects such as the demographic density, the urban conformation and traffic management, the characteristics and the dimension of the human activities. In this respect, we speculated that the more urbanised cities may be considered greater sources of air-FA, representing a potential additional risky condition for health, compared to smaller cities.

This cross-sectional study aims to evaluate the role of FA exposure and the urbanisation level on OS induction, quantified by urinary 15-F2t-Isoprostane (15-F2t-IsoP), and on airway inflammation, measured by the fraction of exhaled nitric oxide (FeNO). It is notable that 15-F2t-IsoP is a reliable and sensitive biomarker of OS, used in several other epidemiological studies $[10,11,16]$. FeNO is measured in a non-invasive way and is a biomarker of eosinophilic airway inflammation, useful in monitoring inflammatory processes due to air pollution exposure [20].

A sample of traffic police officers from Turin and Pavia, two north-western Italian cities with different levels of urbanisation, was enrolled.

\section{Materials and Methods}

In total, 154 traffic police officers were enrolled in this study from November 2015 to March 2016; 109 of them were from Turin and 45 from a smaller town, Pavia. Turin $(886,837$ inhabitants) is located $239 \mathrm{~m}$ above sea level (a.s.l.), and has a population density per $\mathrm{km}^{2}$ equal to 6813 , while Pavia (72,612 inhabitants) is located 77 a.s.l. and has a population density equal to 1155 per $\mathrm{km}^{2}$. Both cities are located in the north-western part of Italy, in the Po Valley (Figure 1), and are approximately $160 \mathrm{~km}$ from each other. The Po Valley $\left(470,000 \mathrm{~km}^{2}\right)$ is one of the largest European plains, and is relatively homogeneous in terms of lifestyle, social and working conditions. In ecological terms, its climate is continental and, due to frequent thermal inversion episodes, vertical and horizontal air exchanges are more difficult compared to other areas of Europe, thus the air quality is poor [22].

The workers eligible to participate in the study were those working as traffic police officers in the urban areas of Turin and Pavia, completing different outdoor tasks such as traffic management (for a maximum of $2 \mathrm{~h}$ per working shift) as well as those working indoors. The invitation to participate was addressed to workers of both sexes and no other exclusion criteria were considered. In total, 154 traffic police officers participated by providing their written informed consent. The epidemiological sample did not involve the enrolment of subjects as controls. This is because the purpose of the study, as previously mentioned, was to compare two urban realities and different tasks, performed indoors and outdoors, without focusing on exposed and unexposed subjects.

On the day set for sampling, the subjects wore during the working shift $(8 \mathrm{~h})$ a personal air-sampler (Radiello ${ }^{\circledR}$ ) to measure air-FA [11] (https://www.restek.com/pdfs/radiello-manual.pdf). At the end of 
the working shift, the traffic police officers filled out a questionnaire and provided a spot of urine for the quantification of 15-F2t-IsoP and cotinine, as biomarkers of OS and tobacco smoking exposure, respectively. Moreover, two groups of pulmonologists measured, at individual level, FeNO as a marker of airway eosinophils inflammation.

This study obtained ethical approval in accordance with the Helsinki Declaration of 1975 (“Fondazione I.R.C.C.S. Policlinico San Matteo, Pavia" protocol number: 20130000718).

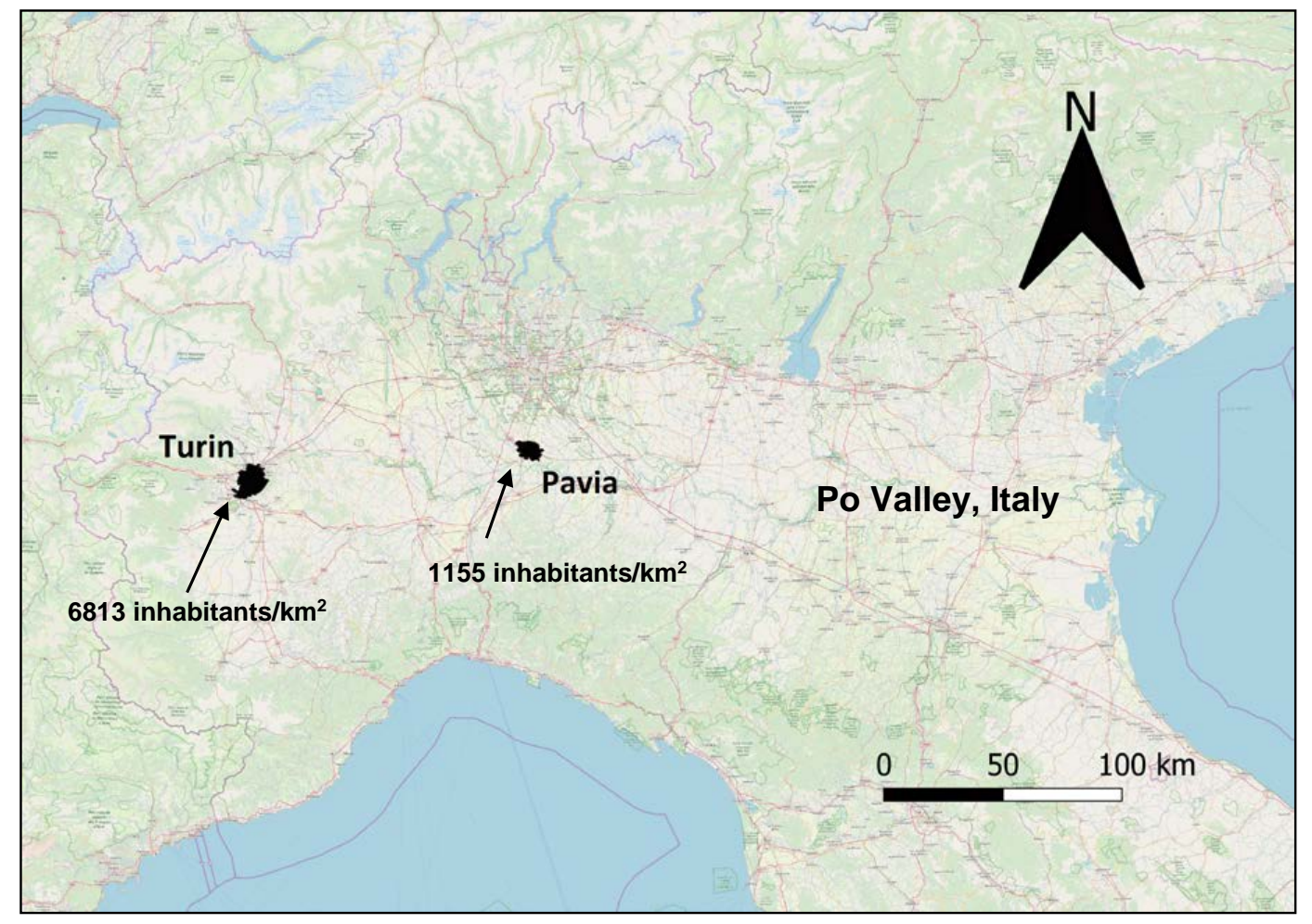

Figure 1. Map showing study area. The human density of the two cities, about $160 \mathrm{~km}$ apart, is reported as inhabitants per square kilometer.

\subsection{Questionnaire}

The same skilled person administered the questionnaire to each subject in the Turin and Pavia headquarters of the traffic police officers, collecting details about anthropometric characteristics, job tasks and location, years of service and potential confounders in OS induction such as diet, physical activity and tobacco smoke habits.

\subsection{Personal Air-FA}

Air-FA samples were collected for a whole working shift $(8 \mathrm{~h})$, using passive personal air samplers working with the radial symmetry (Radiello ${ }^{\circledR}$ ), clipped near the breathing zone of the subject. The personal air samplers were equipped with a specific sorbent tube containing a 35-50 florisil mesh coated with 2,4-dinitrophenylhydrazine (DNPH). DNPH reacts with FA yielding 2,4-dinitrophenylhydrazone, which was subsequently quantified by high performance liquid chromatography (HPLC) according to the NIOSH method No. 2016 [23]. Briefly: the sampling rate value Q for Radiello ${ }^{\circledR}$ at $298 \mathrm{~K}\left(25^{\circ} \mathrm{C}\right)$ and $1013 \mathrm{hPa}$ is 99 , the linearity range in $\mu \mathrm{g} / \mathrm{m}^{3}$ is $1000 \div 4,000,000$, the limit of quantitation is $\mu \mathrm{g} / \mathrm{m}^{3}=0.1$, and uncertainty is at $2 \sigma \%$, is 13.8 .

The following materials are required to proceed with desorption: HPLC or spectroscopy grade acetonitrile, class A volumetric pipette, capacity $2 \mathrm{~mL}$, micropore filter membranes, porosity $0.45 \mu \mathrm{m}$, solvent resistant. Procedure: $2 \mathrm{~mL}$ acetonitrile were introduced directly in the cartridge tube, recap and stir from time to time for $30 \mathrm{~min}$. The resulting solution was filtered and kept well capped until analysis 
time. When the analysis was delayed, the solution was stored at $4{ }^{\circ} \mathrm{C}$. Materials for instrumental analysis: reverse phase C18 HPLC column, length $150 \mathrm{~mm}, 4.6 \mathrm{~mm}$ diameter, $5 \mu \mathrm{m}$ packing particle size. The HPLC apparatus was capable of elution gradient and UV detection. Procedure: the detector was set at a wavelength of $365 \mathrm{~nm}$. Between 10 and $50 \mu \mathrm{L}$ of the solution was injected and eluted at flow of $1.9 \mathrm{~mL} \cdot \mathrm{min}-1$. An isocratic elution was done with acetonitrile/water 38:62 v/v for $10 \mathrm{~min}$, up to acetonitrile/water 75:25 v/v in $10 \mathrm{~min}$, and reverse gradient to acetonitrile/water 38:62 v/v in $5 \mathrm{~min}$. Finally, the detection limit was calculated as the sample concentration, providing a signal-to-noise ratio of 3. The quantification limit was considered to be twice when compared to the detection limit: $0.10 \mu \mathrm{g} \mathrm{mL}^{-1}$ and $0.05 \mu \mathrm{g} \mathrm{mL}{ }^{-1}$ respectively. The $\mathrm{CV}$ values were $<5 \%$.

\subsection{Biological Analyses}

Urinary samples were collected at the end of the working shift, divided into aliquots, and stored at $-80{ }^{\circ} \mathrm{C}$ until analyses. In order to normalise the individual excretion rate of all biological parameters, the first aliquot was used to quantify the urinary creatinine concentration by the Kinetic Jaffé method [24]. Since active and passive tobacco smoke exposure may exert its pro-oxidant effect acting as a potential confounder, urinary cotinine was measure in another aliquot, using a specific ELISA kit (Abnova Corporation, Jhongli, Taiwan) following the manufacturer's instructions. Finally, the 15-F2t-IsoP was quantified by the ELISA technique following the manufacturer's instructions [16].

\subsection{FeNO Measurements}

FeNO was measured in accordance with the American Thoracic Society and European Respiratory Society recommendations [25], by the CLD 88 chemiluminescence analyser (Eco Medics, Durnten, Switzerland), at an exhaled flow of $50 \mathrm{~mL} / \mathrm{s}$ and given in part per billion (instrument limit values ranging between $0.1-5000 \mathrm{ppb}$ ). The same group of pulmonologists performed the measurements in the Turin and Pavia traffic police officer headquarters. Participants were requested to refrain from smoking, eating, drinking and doing strenuous exercise for one hour prior to the measurement. The instrument was turned on at least $15 \mathrm{~min}$ prior to use and set for a $10 \mathrm{~s}$ inhalation. Each subject underwent measurement after receiving detailed explanations by the personnel. A nearby mirror helped participants in exhaling at the correct speed. All subjects were in sitting position and were asked to empty their lungs through a single long exhalation and to exhale slowly and steadily into the mouthpiece. If the participants were unable to complete the test at the first attempt, more attempts, no more than nine per person, were repeated and recorded.

\subsection{Statistical Analysis}

Descriptive analyses were carried out with the chi-square test for categorical variables (gender, job duties, cities), and the t-test or Mann-Whitney U-test for quantitative parameters (age, BMI, FeNO, cotinine, 15-F2t-IsoP, and FA), as appropriate. Correlation analyses were performed using the non-parametric Spearman's test to investigate the correlations between the biomarkers of OS and tobacco smoke exposure (15-F2t-IsoP and cotinine) and of OS and personal air-FA (15-F2t-IsoP and FA). A logarithmic transformation (Log-e) was performed for all the variables that showed a non-normal distribution (15-F2t-IsoP and FA); the normality of the distribution was tested using the Shapiro-Wilk test. Multiple linear regression (MLR) models were used to test the relationship and strength of the association between the dependent variable, independent variable and covariates or confounders (sex, tobacco smoke, sampling location, and job duties, depending on the specific model). MLR is an extension of ordinary least squares (OLS) regression involving more than one explanatory variable. MLR has been used to check the association between dependent and independent variables, mainly based on their approximately linear relationship and on the absence of collinearity among the covariates. The most parsimonious model has been selected, comparing several models that included a different set of variables, selected by a stepwise method. All categorical variables included in the model were dichotomous (0-1). 
Moreover, the analysis on predictive margins was performed to deeply investigate the influence of job duties on FA exposure between the two locations, the difference of 15-F2t-IsoP between Turin and Pavia, controlling for personal air-FA and FeNO variation among venues controlling for both FA and cotinine. The level of significance was set at $p \leq 0.05$ (two-tailed) for all tests. All analyses were performed using STATA SE v14.2 (Stata Corp, College Station, TX, USA).

\section{Results}

Table 1 reports the general details of the epidemiological sampling between the two cities. Although more police officers were sampled in Turin (71\%) than in Pavia (29\%), no differences were observed in the distribution of age, BMI, gender and job duties (carried out indoors and outdoors) between the two cities. As shown in Table 2, the mean values of urinary 15-F2t-IsoP and FeNO are significantly different across locations (both $p<0.001$ ), as well as personal exposure levels of air-FA $(p<0.001)$. Conversely, urinary cotinine shows similar distributions among subjects working in the two sampling locations, highlighting that both considered populations show similar smoking habits.

Table 1. Numerical and percentage characteristics of subjects. The statistical differences between the two cities are reported. Age: Mann-Whitney (M-W) U-test, BMI t-test; gender and job duties: $\mathrm{X}$-square test.

\begin{tabular}{|c|c|c|c|c|c|}
\hline & & $\begin{array}{c}\text { Turin } N=109 \\
(71 \%)\end{array}$ & $\begin{array}{c}\text { Pavia } N=45 \\
(29 \%)\end{array}$ & $p$-Value & Overall $n=154$ \\
\hline \multicolumn{2}{|c|}{ Age (years) } & $45.5 \pm 7.7$ & $46.6 \pm 7.6$ & 0.390 & $45.8 \pm 7.7$ \\
\hline \multicolumn{2}{|c|}{ BMI $\left(\mathrm{kg} / \mathrm{m}^{2}\right)$} & $24.8 \pm 3.7$ & $24.1 \pm 3.2$ & 0.236 & $24.6 \pm 3.6$ \\
\hline \multirow{2}{*}{ Gender } & Females & $50(46)$ & $16(36)$ & \multirow{2}{*}{0.153} & $66(43 \%)$ \\
\hline & Males & $59(54)$ & $29(64)$ & & $88(57 \%)$ \\
\hline \multirow{2}{*}{ Job Duties } & Indoor & $59(54)$ & $26(58)$ & \multirow{2}{*}{0.765} & $85(55 \%)$ \\
\hline & Outdoor & $50(46)$ & $19(42)$ & & $69(45 \%)$ \\
\hline
\end{tabular}

Table 2. General description of environmental and biological measurements presented as subgroups by city. The statistical differences between the two cities are reported (M-W U-test).

\begin{tabular}{ccccc}
\hline & Turin & Pavia & $p$-Value & Overall \\
\hline FeNO $(\mathbf{p p b})$ & $37.7 \pm 28.3$ & $33.6 \pm 48.4$ & $<0.001$ & $36.5 \pm 35.2$ \\
\hline 15-F2t-IsoP $(\mathbf{n g} / \mathbf{m g}$ of Creatinine) & $9.1 \pm 7.3$ & $4.1 \pm 2.1$ & $<0.001$ & $7.7 \pm 6.7$ \\
\hline FA $\left(\boldsymbol{\mu g} / \mathbf{m}^{\mathbf{3}}\right)$ & $30.9 \pm 9.8$ & $17.5 \pm 4.7$ & $<0.001$ & $27.0 \pm 10.5$ \\
\hline Cotinine $(\mathbf{n g} / \mathbf{m g}$ of Creatinine) & $15.4 \pm 22.8$ & $14.9 \pm 28.9$ & 0.641 & $15.4 \pm 23.4$ \\
\hline
\end{tabular}

As depicted in Figure 2, air-FA and 15-F2t-IsoP are significantly and positively correlated (Spearman's rho $=0.241, p=0.003$ ). The MLR model, adjusted for job duties and sex, shows that traffic police officers working in Turin have a significantly higher level of log (air-FA), 53.6\% more than workers in Pavia $(p<0.001)$. In particular, the two $\log$ (air-FA) mean values are 3.38 (C.I. $95 \%$ 3.33-3.43) in the traffic police officers working in Turin and 2.84 (C.I. 95\% 2.77-2.92) in the traffic police officers working in Pavia. Moreover, controlling for sex and city, log (air-FA) is significantly higher in traffic police officers who carried out their job duties mostly outdoors (3.18, C.I. 95\% 3.13-3.24, $p=0.035$ ), with an increase of $9.3 \%$ compared to traffic police officers working indoors (Figure 3A). The analyses of the OS biomarker highlight that, controlling for log (air-FA), the levels of 15-F2t-IsoP remain significantly higher $(+66.8 \%)$ in traffic police officers working in Turin, compared with those employed in Pavia $(p<0.001)$ (Figure 3B). Furthermore, the MLR model adjusted for the level of cotinine and for air-FA exposure shows that traffic police officers working in Turin have significant higher levels of FeNO (+75\%) compared to those working in Pavia $(p<0.001)$ (Figure 3C). Finally, 
FeNO is negatively correlated with urinary cotinine, thus with tobacco smoke exposure. Although not significantly $(p=0.07)$, this tendency is consistent with previous studies [26-29].

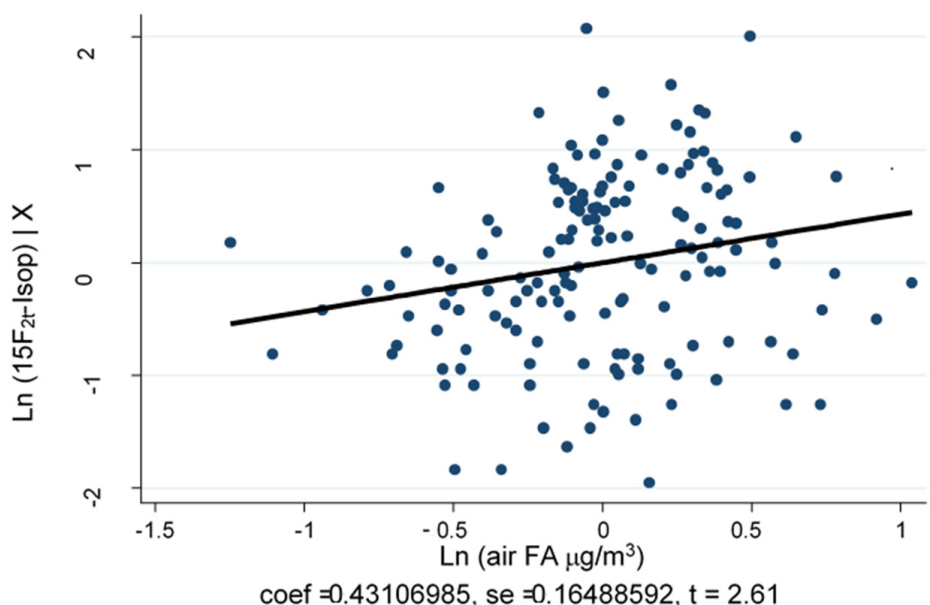

Figure 2. Correlation between Air-formaldehyde (FA) and $15-\mathrm{F}_{2 \mathrm{t}}-\mathrm{IsoP}$. The correlation is significant and positive (Spearman's rho $=0.241, p=0.003$ ).

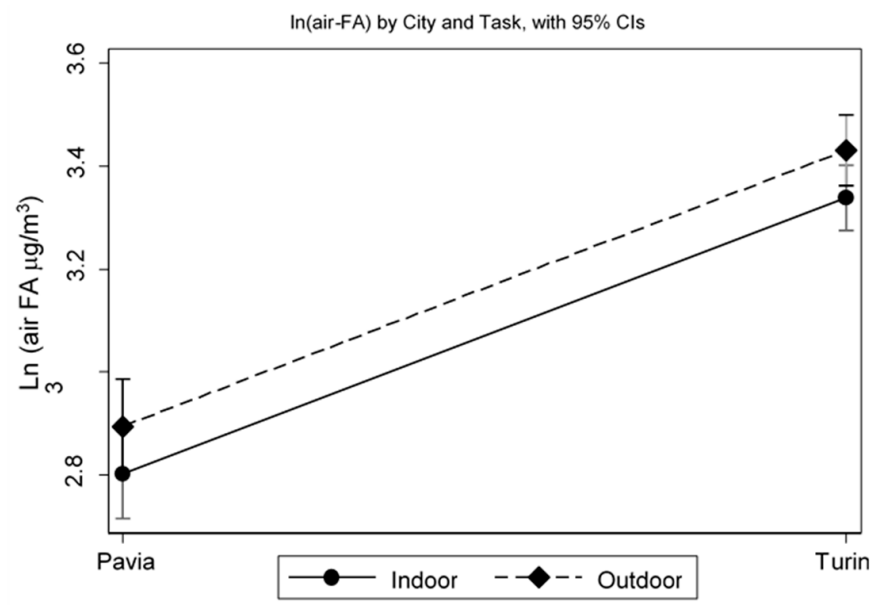

(A)

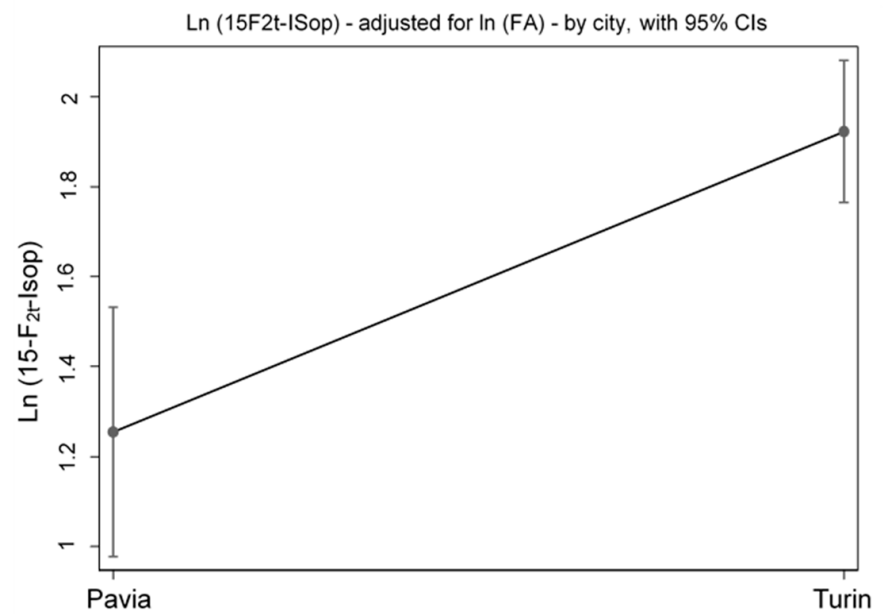

(B)

Figure 3. Cont. 


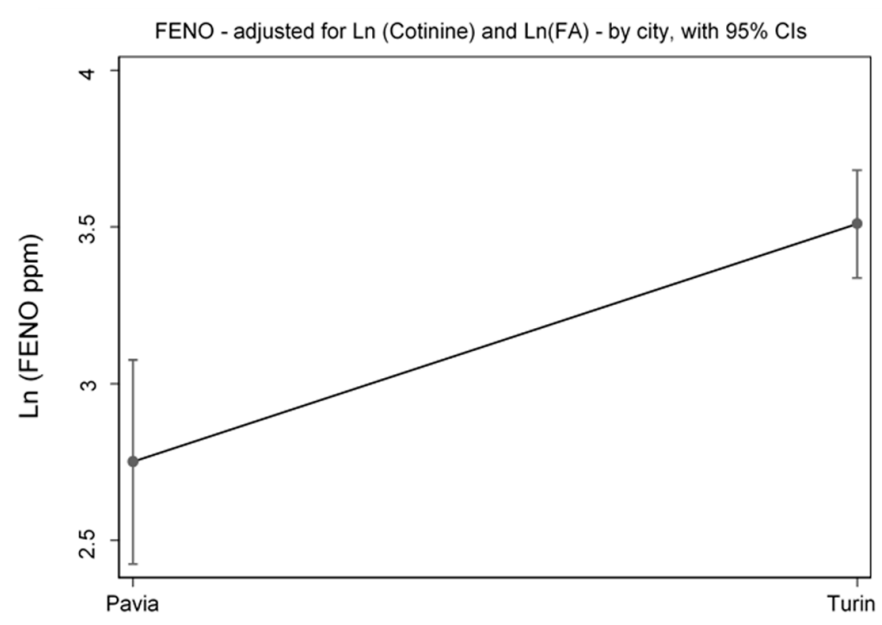

(C)

Figure 3. MLR model. Log (air-FA), in Turin and in Pavia, indoors and outdoors (A), Log (15 F2t-IsoP) (B) and $\log (\mathrm{FeNO})(\mathrm{C})$.

\section{Discussion}

Air pollution is a matter of concern for human health due to its potential toxicological and/or carcinogenic effects on humans. Long-term exposures to air pollution, although in low doses, are recognised risk factors for the onset or exacerbation of several diseases, including respiratory infections and inflammations, cardiovascular impairments and cancer [30-32]. Among airborne VOCs, FA gained attention because of its toxicological and carcinogenic properties and for its primary and secondary origin in urban ambient air [12]. FA levels usually range between 1 and $20 \mu \mathrm{g} / \mathrm{m}^{3}$ in urban air [33,34], with measurements that are usually higher in personal air compared to those measured by fixed samplers. This difference may depend on the complexity of the scenario described by the personal air-samplers. In fact, they are able to quantify a more comprehensive exposure accounting for all locations visited by the subjects.

In indoor environments, sources emitting FA are numerous, and air exchanges and dilutions processes are scarcer than in outdoor environments $[8,35,36]$. However, this study analysed a specific scenario of exposure, because the traffic police officers spend most of their working shift outdoors, differently from many other workers. Specifically, exposure to air-FA of traffic police officers is significantly higher in Turin than in Pavia, the smaller town. This result may depend on the different level of urbanisation.

Limiting the observation to outdoor pollution, the Po Valley is one of the most polluted areas in Europe. The orographic barriers enclose this area, characterised by weak winds and depressed surface; these factors provide less chances of air dilution processes, keeping the concentrations of air pollution high [37-40].

As above-mentioned, Turin and Pavia have different population densities and different air-FA concentrations. Besides the general ambient air quality in the two different urban contexts, this result emphasises the importance of traffic-related air-FA exposure. Additionally, the use of personal air-samplers has adequately characterised the individual exposures, allowing deeper investigations about the potential biological effects and health risks for the workers who participated in the study.

The analyses of general OS and local airways inflammation confirm that air pollution, tobacco smoking and air-FA exposures are able to determine biological effects, reflecting the interaction between environment and human exposure. Furthermore, our results show that the OS biomarker is significantly and positively correlated with both air-FA exposures and urinary cotinine (both $p<0.001$ ). Interestingly, 15-F2t-IsoP is higher in traffic police officers employed in Turin if compared to those working in Pavia, even controlling for FA exposures. The model adjusted for cotinine, diet, and BMI 
did not reach statistical significance, suggesting that other factors, not considered in this study, could contribute to determining an increase of $15-\mathrm{F} 2 \mathrm{t}-\mathrm{IsoP}$, which remains aspecific, besides its reliability in assessing OS status. Nevertheless, the modification of the behaviour of isoprostane only for FA appears to be a finding of considerable importance, even if the correlations are weak.

The traffic police officers of the two cities report a FeNO mean value ranging from 25 to $50 \mathrm{ppb}$. In particular, higher FeNO levels were recorded in the traffic police officers of Turin. Nevertheless, no correlations were found between FeNO and FA, 15-F2t-IsoP and cotinine, respectively. Unlike other studies [41,42], our findings do not show higher FeNO levels in men, nor in older subjects. FeNO levels measured in our study were classified as "intermediate FeNO", according to ATS [43] guidelines, which state that cautious interpretation is required at these values, considering the clinical contexts and the individual characteristics of the subjects (e.g., age and gender).

Differently from other authors [42], no relation has been found between FeNO and allergies. Finally, adjusting for sampling locations, FeNO shows a negative association with cotinine levels, although not significant $(p=0.07)$. This result is consistent with previous studies $[41,44,45]$, since tobacco smoke is a recognised factor in the downregulation of the nitric oxide synthase, resulting in lower FeNO levels [42]. At this concern, several mechanisms have been proposed to explain the influence of tobacco smoke on FeNO levels. Nitrogen oxide in respiratory tract originates from inducible NO synthase (iNOS), regulated by interferon gamma (IFN- $\gamma$ ). Tobacco smoke may interfere in this pathway by reducing IFN- $\gamma$ or directly inducing oxidative processes in the airways leading to the scavenging of NO [44].

\section{Conclusions}

In conclusion, our results suggest that even low doses and relatively small differences among environmental air-FA exposures may contribute to OS induction and airways inflammation. Traffic-related emissions and population densities play an important role in the air pollution exposure of workers who carry out their job duties mostly outdoors, as the traffic police officers do. These latter are exposed to a wide range of airborne pollutants, many of which are capable of inducing oxidative stress and airways inflammation.

Personal exposure measurements, quantified by personal air-samplers, are more accurate than those measured by fixed samplers and better represent the air quality, especially in complex environments such as the urban air. In other words, fixed sampling stations of the Regional Agency for the Protection of the Environment (A.R.P.A.) were not able to accurately describe the individual exposure to air pollutants during the working shift. There are five fixed sampling stations in Turin and two in Pavia, while the personal samplers have been worn by each worker $(n=154)$. Finally, FA is not regularly sampled by fixed sampling stations of A.R.P.A.

A limitation of this study is that only the exposure to FA was measured. However, FeNO, OS, tobacco smoke and air-FA were quantified by standardised and reproducible methods; thus, the comparison between two different polluted cities, located within the same geographic area in the south part of Europe, underlines the role of the urbanisation as an environmental human health risk factor. Future perspectives in this sense may drive further analyses such as the "greyness" quantification in urban environment, in order to better understand how the urbanisation interacts with human exposure and the consequent human health risk.

The traffic police officers working in Turin displayed higher levels of all measured biomarkers, with the exception of cotinine, a biomarker of exposure to tobacco smoke. Overall, these data highlight the influence of the living environment on the biological parameters, showing its influence on both local and general OS and inflammation.

Further investigations could consider a multiple airborne pollutants analysis, also a multi-site sampling for more comprehensive comparisons on the urbanisation levels. 
In the future, additional analyses on urban settings, such as greyness/greenness quantification [46], may be helpful in driving new preventive strategies related to urban management, for outdoor workers and the general population.

Author Contributions: Conceptualization, R.B., A.C., E.G.; Methodology, V.B., P.P., E.G.; Validation, G.S., V.B.; Formal Analysis, G.S., V.B., A.G., P.P., F.G.; Investigation and samplings, G.S., V.B., A.G., F.G.; Writing-Original Draft Preparation, G.S., P.P., R.B.; Writing-Review and Editing, R.B., A.C., F.G.; Supervision, R.B. All authors have read and agreed to the published version of the manuscript.

Funding: This research did not receive any specific grant from funding agencies in the public, commercial, or not-for-profit sectors.

Acknowledgments: Many thanks are due to all traffic police officers of Turin and Pavia for their willing cooperation.

Conflicts of Interest: The authors declare no conflict of interest.

\section{References}

1. Nurmatov, U.B.; Tagiyeva, N.; Semple, S.; Devereux, G.; Sheikh, A. Volatile organic compounds and risk of asthma and allergy: A systematic review. Eur. Respir. Rev. 2015, 24, 92-101. [CrossRef] [PubMed]

2. Montero-Montoya, R.; López-Vargas, R.; Arellano-Aguilar, O. Volatile Organic Compounds in Air: Sources, Distribution, Exposure and Associated Illnesses in Children. Ann. Glob. Health 2018, 84, 225-238. [CrossRef] [PubMed]

3. Raysoni, A.U.; Stock, T.H.; Sarnat, J.A.; Chavez, M.C.; Sarnat, S.E.; Montoya, T.; Holguin, F.; Li, W.W. Evaluation of VOC concentrations in indoor and outdoor microenvironments at near-road schools. Environ. Pollut. 2017, 231, 681-693. [CrossRef] [PubMed]

4. Bazyar, J.; Pourvakhshoori, N.; Khankeh, H.; Farrokhi, M.; Delshad, V.; Rajabi, E. A comprehensive evaluation of the association between ambient air pollution and adverse health outcomes of major organ systems: A systematic review with a worldwide approach. Environ. Sci. Pollut. Res. 2019, 26, 12648-12661. [CrossRef]

5. Shuai, J.; Kim, S.; Ryu, H.; Park, J.; Lee, C.K.; Kim, G.-B.; Ultra, V.U.; Yang, W. Health risk assessment of volatile organic compounds exposure near Daegu dyeing industrial complex in South Korea. BMC Public Health 2018, 18, 528. [CrossRef]

6. Bari, M.A.; Kindzierski, W.B. Ambient volatile organic compounds (VOCs) in Calgary, Alberta: Sources and screening health risk assessment. Sci. Total Environ. 2018, 631-632, 627-640. [CrossRef]

7. Salthammer, T. Data on formaldehyde sources, formaldehyde concentrations and air exchange rates in European housings. Data Brief 2019, 22, 400-435. [CrossRef]

8. Bono, R.; Degan, R.; Pazzi, M.; Romanazzi, V.; Rovere, R. Benzene and formaldehyde in air of two winter Olympic venues of "Torino 2006". Environ. Int. 2010, 36, 269-275. [CrossRef]

9. Lui, K.H.; Ho, S.S.H.; Louie, P.K.K.; Chan, C.S.; Lee, S.C.; Hu, D.; Chan, P.W.; Lee, J.C.W.; Ho, K.F. Seasonal behavior of carbonyls and source characterization of formaldehyde (HCHO) in ambient air. Atmos. Environ. 2017, 152, 51-60. [CrossRef]

10. Bono, R.; Capacci, F.; Cellai, F.; Sgarrella, C.; Bellisario, V.; Trucco, G.; Tofani, L.; Peluso, A.; Poli, C.; Arena, L.; et al. Wood dust and urinary 15-F2t isoprostane in Italian industry workers. Environ. Res. 2019, 173, 300-305. [CrossRef]

11. Bellisario, V.; Mengozzi, G.; Grignani, E.; Bugiani, M.; Sapino, A.; Bussolati, G.; Bono, R. Towards a formalin-free hospital. Levels of 15-F2t-isoprostane and malondialdehyde to monitor exposure to formaldehyde in nurses from operating theatres. Toxicol. Res. 2016, 5, 1122-1129. [CrossRef] [PubMed]

12. IARC Working Group on the Evaluation of Carcinogenic Risks to Humans; World Health Organization; International Agency for Research on Cancer. Formaldehyde, 2-Butoxyethanol and 1-tert-Butoxypropan-2-ol; International Agency for Research on Cancer: Lyon, France, 2006; ISBN 9283212886.

13. US EPA National Center for Environmental Assessment. IRIS Toxicological Review of Formaldehyde (Inhalation) (External Review Draft 2010); Glenn, B., Ed.; US EPA National Center for Environmental Assessment: Washington, DC, USA, 2010.

14. McGwin, G.; Lienert, J.; Kennedy, J.I. Formaldehyde exposure and asthma in children: A systematic review. Environ. Health Perspect. 2010, 118, 313-317. [CrossRef] [PubMed] 
15. Bono, R.; Romanazzi, V.; Munnia, A.; Piro, S.; Allione, A.; Ricceri, F.; Guarrera, S.; Pignata, C.; Matullo, G.; Wang, P.; et al. Malondialdehyde-deoxyguanosine adduct formation in workers of pathology wards: The role of air formaldehyde exposure. Chem. Res. Toxicol. 2010, 23, 1342-1348. [CrossRef] [PubMed]

16. Romanazzi, V.; Pirro, V.; Bellisario, V.; Mengozzi, G.; Peluso, M.; Pazzi, M.; Bugiani, M.; Verlato, G.; Bono, R. 15-F2t isoprostane as biomarker of oxidative stress induced by tobacco smoke and occupational exposure to formaldehyde in workers of plastic laminates. Sci. Total Environ. 2013, 442, 20-25. [CrossRef]

17. Santovito, A.; Schilirò, T.; Castellano, S.; Cervella, P.; Bigatti, M.P.; Gilli, G.; Bono, R.; DelPero, M. Combined analysis of chromosomal aberrations and glutathione S-transferase M1 and T1 polymorphisms in pathologists occupationally exposed to formaldehyde. Arch. Toxicol. 2011, 85, 1295-1302. [CrossRef]

18. Bono, R.; Munnia, A.; Romanazzi, V.; Bellisario, V.; Cellai, F.; Peluso, M.E.M. Formaldehyde-induced toxicity in the nasal epithelia of workers of a plastic laminate plant. Toxicol. Res. 2016, 5, 752-760. [CrossRef]

19. Lanki, T.; Hampel, R.; Tiittanen, P.; Andrich, S.; Beelen, R.; Brunekreef, B.; Dratva, J.; De Faire, U.; Fuks, K.B.; Hoffmann, B.; et al. Air pollution from road traffic and systemic inflammation in adults: A cross-sectional analysis in the European ESCAPE project. Environ. Health Perspect. 2015, 123, 785-791. [CrossRef]

20. Duong, A.; Steinmaus, C.; McHale, C.M.; Vaughan, C.P.; Zhang, L. Reproductive and developmental toxicity of formaldehyde: A systematic review. Mutat. Res. 2011, 728, 118-138. [CrossRef]

21. Pidoux, G.; Gerbaud, P.; Guibourdenche, J.; Thérond, P.; Ferreira, F.; Simasotchi, C.; Evain-Brion, D.; Gil, S. Formaldehyde crosses the human placenta and affects human trophoblast differentiation and hormonal functions. PLOS ONE 2015, 10, e0133506. [CrossRef]

22. Diémoz, H.; Barnaba, F.; Magri, T.; Pession, G.; Dionisi, D.; Pittavino, S.; Tombolato, I.K.F.; Campanelli, M.; Della Ceca, L.S.; Hervo, M.; et al. Transport of Po Valley aerosol pollution to the northwestern Alps-Part 1: Phenomenology. Atmos. Chem. Phys. 2019, 19, 3065-3095. [CrossRef]

23. US EPA. O. NIOSH Method 2016: Formaldehyde. Available online: https://www.epa.gov/esam/nioshmethod-2016-formaldehyde (accessed on 4 March 2020).

24. Bartels, H.; Cikes, M. Über chromogene der kreatininbestimmung nach Jaffé. Clin. Chim. Acta 1969, 26, 1-10. [CrossRef]

25. Exhaled, N.O. ATS/ERS recommendations for standardized procedures for the online and offline measurement of exhaled lower respiratory nitric oxide and nasal nitric oxide, 2005. Am. J. Respir. Crit. Care Med. 2005, 171, 912-930.

26. Olin, A.C.; Rosengren, A.; Thelle, D.S.; Lissner, L.; Bake, B.; Torén, K. Height, age, and atopy are associated with fraction of exhaled nitric oxide in a large adult general population sample. Chest 2006, 130, 1319-1325. [CrossRef]

27. Bommarito, L.; Migliore, E.; Bugiani, M.; Heffler, E.; Guida, G.; Bucca, C.; De Marco, R.; Rolla, G. Exhaled nitric oxide in a population sample of adults. Respiration 2008, 75, 386-392. [CrossRef] [PubMed]

28. Xu, X.; Hu, H.; Kearney, G.D.; Kan, H.; Carrillo, G.; Chen, X. A population-based study of smoking, serum cotinine and exhaled nitric oxide among asthmatics and a healthy population in the USA. Inhal. Toxicol. 2016, 28, 724-730. [CrossRef] [PubMed]

29. Bobrowska-Korzeniowska, M.; Stelmach, I.; Brzozowska, A.; Jerzyńska, J.; Mitał, M.; Stelmach, W. The effect of passive smoking on exhaled nitric oxide in asthmatic children. Nitric Oxide 2019, 86, 48-53. [CrossRef] [PubMed]

30. Brucker, N.; Charão, M.F.; Moro, A.M.; Ferrari, P.; Bubols, G.; Sauer, E.; Fracasso, R.; Durgante, J.; Thiesen, F.V.; Duarte, M.M.; et al. Atherosclerotic process in taxi drivers occupationally exposed to air pollution and co-morbidities. Environ. Res. 2014, 131, 31-38. [CrossRef]

31. Yamamoto, S.S.; Phalkey, R.; Malik, A.A. A systematic review of air pollution as a risk factor for cardiovascular disease in South Asia: Limited evidence from India and Pakistan. Int. J. Hyg. Environ. Health 2014, 217, 133-144. [CrossRef]

32. Zhang, W.; Qian, C.-N.; Zeng, Y.-X. Air pollution: A smoking gun for cancer. Chin. J. Cancer 2014, 33, $173-175$. [CrossRef]

33. Kheirbek, I.; Johnson, S.; Ross, Z.; Pezeshki, G.; Ito, K.; Eisl, H.; Matte, T. Spatial variability in levels of benzene, formaldehyde, and total benzene, toluene, ethylbenzene and xylenes in New York City: A land-use regression study. Environ. Health 2012, 11, 51. [CrossRef] 
34. Marcon, A.; Fracasso, M.E.; Marchetti, P.; Doria, D.; Girardi, P.; Guarda, L.; Pesce, G.; Pironi, V.; Ricci, P.; de Marco, R. Outdoor formaldehyde and NO2 exposures and markers of genotoxicity in children living near chipboard industries. Environ. Health Perspect. 2014, 122, 639-645. [CrossRef] [PubMed]

35. Maître, A.; Soulat, J.-M.; Masclet, P.; Stoklov, M.; Marquès, M.; de Gaudemaris, R. Exposure to carcinogenic air pollutants among policemen working close to traffic in an urban area. Scand. J. Work. Environ. Health 2002, 28, 402-410. [CrossRef] [PubMed]

36. Lazenby, V.; Hinwood, A.; Callan, A.; Franklin, P. Formaldehyde personal exposure measurements and time weighted exposure estimates in children. Chemosphere 2012, 88, 966-973. [CrossRef] [PubMed]

37. Traversi, D.; Degan, R.; De Marco, R.; Gilli, G.; Pignata, C.; Ponzio, M.; Rava, M.; Sessarego, F.; Villani, S.; Bono, R. Mutagenic properties of PM2. 5 air pollution in the Padana Plain (Italy) before and in the course of XX Winter Olympic Games of “Torino 2006." Environ. Int. 2008, 34, 966-970.

38. Carbone, C.; Decesari, S.; Mircea, M.; Giulianelli, L.; Finessi, E.; Rinaldi, M.; Fuzzi, S.; Marinoni, A.; Duchi, R.; Perrino, C.; et al. Size-resolved aerosol chemical composition over the Italian Peninsula during typical summer and winter conditions. Atmos. Environ. 2010, 44, 5269-5278. [CrossRef]

39. Ferrero, L.; Riccio, A.; Perrone, M.G.; Sangiorgi, G.; Ferrini, B.S.; Bolzacchini, E. Mixing height determination by tethered balloon-based particle soundings and modeling simulations. Atmos. Res. 2011, 102, 145-156. [CrossRef]

40. European Environment Agency. Air Quality in Europe-2014 Report; European Environment Agency: Copenhagen, Denmark, 2014.

41. Nerpin, E.; Olivieri, M.; Gislason, T.; Olin, A.C.; Nielsen, R.; Johannessen, A.; Ferreira, D.S.; Marcon, A.; Cazzoletti, L.; Accordini, S.; et al. Determinants of fractional exhaled nitric oxide in healthy men and women from the European Community Respiratory Health Survey III. Clin. Exp. Allergy 2019, 49, 969-979. [CrossRef]

42. Olin, A.-C. Induced sputum, exhaled nitric oxide, and particles in exhaled air in assessing airways inflammation in occupational exposures. Clin. Chest Med. 2012, 33, 771-782. [CrossRef]

43. Dweik, R.A.; Boggs, P.B.; Erzurum, S.C.; Irvin, C.G.; Leigh, M.W.; Lundberg, J.O.; Olin, A.C.; Plummer, A.L.; Taylor, D.R. An official ATS clinical practice guideline: Interpretation of exhaled nitric oxide levels (FENO) for clinical applications. Am. J. Respir. Crit. Care Med. 2011, 184, 602-615. [CrossRef]

44. Jacinto, T.; Malinovschi, A.; Janson, C.; Fonseca, J.; Alving, K. Differential effect of cigarette smoke exposure on exhaled nitric oxide and blood eosinophils in healthy and asthmatic individuals. J. Breath Res. 2017, 11, 036006. [CrossRef]

45. Torén, K.; Murgia, N.; Schiöler, L.; Bake, B.; Olin, A.C. Reference values of fractional excretion of exhaled nitric oxide among non-smokers and current smokers. BMC Pulm. Med. 2017, 17, 118. [CrossRef] [PubMed]

46. Squillacioti, G.; Bellisario, V.; Levra, S.; Piccioni, P.; Bono, R. Greenness availability and respiratory health in a population of urbanised children in North-Western Italy. Int. J. Environ. Res. Public Health 2020, 17, 108. [CrossRef] [PubMed]

(C) 2020 by the authors. Licensee MDPI, Basel, Switzerland. This article is an open access article distributed under the terms and conditions of the Creative Commons Attribution (CC BY) license (http://creativecommons.org/licenses/by/4.0/). 